\title{
Endoscopic radial artery harvesting for coronary artery bypass grafting
}

\author{
Ajita Naik ${ }^{1^{*}}$, Mohamed Rahouma ${ }^{1 *}$, Cristiano Spadaccio ${ }^{2,3}$, Kritika Mehta1, Massimo Baudo ${ }^{1}$, Mohamed

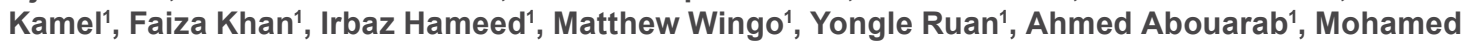 \\ Hossny ${ }^{1}$, Leonard N. Girardi', Mario Gaudino ${ }^{1}$ \\ 'Department of Cardiothoracic Surgery, Weill Cornell Medicine, NY 10065, USA. \\ 2Department of Cardiothoracic Surgery, Golden Jubilee National Hospital, Clydebank, Glasgow G814DY, UK. \\ ${ }^{3}$ Institute of Cardiovascular and Medical Sciences, Veterinary and Life Sciences, College of Medical, University of Glasgow, \\ Glasgow G128QQ, UK. \\ *The two authors made equal contributions.
}

Correspondence to: Dr. Mohamed Rahouma, Department of Cardiothoracic Surgery, Weill Cornell Medicine, 525 East 68 th Street, Box 110, NY 10065, USA. E-mail: mhmdrahouma@gmail.com

How to cite this article: Naik A, Rahouma M, Spadaccio C, Mehta K, Baudo M, Kamel M, Khan F, Hameed I, Wingo M, Ruan Y, Abouarab A, Hossny M, Girardi LN, Gaudino M. Endoscopic radial artery harvesting for coronary artery bypass grafting. Vessel Plus 2018;2:38. http://dx.doi.org/10.20517/2574-1209.2018.62

\begin{abstract}
Received: 3 Aug 2018 First Decision: 11 Sep 2018 Revised: 29 Sep 2018 Accepted: 29 Sep 2018 Published: 7 Nov 2018
Science Editor: Mario F. L. Gaudino Copy Editor: Cai-Hong Wang Production Editor: Zhong-Yu Guo
\end{abstract}

\begin{abstract}
This article summarizes the current research on endoscopic technique of radial artery harvesting as a graft for coronary artery bypass grafting (CABG) surgery. Based on the available data, we reviewed various grafts available for CABG. Radial artery as a graft in CABG surgery has recently gained popularity. We sought to investigate the impact of radial artery harvesting techniques on clinical outcomes. Endoscopic harvest approach was found to be feasible in all patients when performed by skillful surgeon while local arm complications were found to be infrequent. However, when compared to open approach for harvest, it takes longer but provides higher patient satisfaction and cosmetic result.
\end{abstract}

Keywords: Endoscopic radial artery harvesting, coronary artery bypass grafting, harvesting techniques, wound complication, endoscopic technique cost, patency rates

\section{INTRODUCTION}

Coronary artery bypass grafting (CABG) is considered one of the mainstays of myocardial revascularization particularly in patients with left main coronary artery disease, multi-vessel coronary artery disease, and diabetes ${ }^{[1,2]}$.

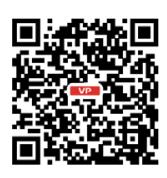


Conduits available in CABG can be broadly classified into arterial and venous grafts. Saphenous vein (SV), Internal Thoracic Artery (ITA), Radial Artery (RA), Ulnar Artery (UA), and right gastroepiploic artery can be used as grafts ${ }^{[3,4]}$. Venous grafts have been found to be more prone to thrombosis, intimal hyperplasia, and atherosclerosis in comparison with arterial grafts ${ }^{[5]}$. Arterial grafts are thus more widely preferred over venous grafts ${ }^{[6]}$.

The RA has been suggested as a suitable conduit for CABG in the $70^{\text {' }}{ }^{[7]}$ in virtue of advantages like uniform size and easy availability ${ }^{[8]}$. Its use was initially abandoned due to concerns of vasospasm, but progressively reconsidered in light of the positive long-term results described in the last decade. At least 6 randomized clinical trials and several observational studies have positively compared patency rates and outcomes of RA vs. RITA and saphenous vein graft (SVG), and very recent evidence from a large patient-level meta-analysis has declared the actual "renaissance" of the RA ${ }^{[\rho]}$. Bilateral internal thoracic artery (BITA) grafting is not widely used due to a higher incidence of sternal complications when compared to single internal thoracic artery grafting (SITA) (0.6\% vs. 1.9\%, 95\% CI: 1.5-6.8) which necessitates additional measures to improve prognosis. Current recommendations are:

Use of ITA in left anterior descending (LAD) bypass in patients where benefits greatly outweigh risks, i.e., when the procedure has to be performed.

An alternative to LITA should be used in patients where benefits outweigh risks, i.e., when additional studies with broad objectives are required.

BITA should be considered in cases where risk of sternal complications is minimal and benefits outweigh risks, i.e., when additional studies with broad objectives are required.

Risk of infection with BITA, should be reduced by skeletonizing the grafts, encouraging smoking cessation, having tight glycemic control, and ensuring adequate sternal stabilization ${ }^{[10]}$.

Both endoscopic and open techniques are available options for RA harvesting and carry different advantages and complications.

This review will focus on RA and will examine the main features of this conduit along with the impact of the available harvesting techniques on clinical outcomes.

\section{PREOPERATIVE CONSIDERATIONS}

While there are no major absolute contraindications to the use of RA, some disadvantages include its increased tendency to spasm owing to a thick tunica media. It is also associated with higher risk of atherosclerosis and intimal hyperplasia compared to $\mathrm{ITA}^{[3]}$. Despite initial reports of lower patency rate of RA grafts in diabetic patients when compared to SVG at 1 year $(89.28 \%$ were patent in RA $v$ s. $97.05 \%$ patent in SVG $)^{[11]}$, the more recent literature and the results of a large patient-level meta-analysis confirm the suitability of RA in diabetics and its theoretical advantage in terms of sternal wound infections when compared to BITA $^{[9,12,13]}$.

Pre-operative suitability of the radial artery is most commonly assessed by the modified Allen's test which is used to determine the patency of the vessels supplying the hand. If the patient's hand flushes within 5-15 s after the examiner releases the occlusive pressure applied on both the RA and the UA, it is considered a positive modified Allen's test. If the hand takes longer than $15 \mathrm{~s}$ the test is considered negative. A positive modified Allen's test translates into good blood circulation in the forearm ${ }^{[14]}$. However, the reliability of this test has been repeatedly questioned. Jarvis et al ${ }^{[15]}$ recommended a Doppler ultrasound to be the gold standard. They 
determined the sensitivity and specificity of the modified Allen's test to be $54.5 \%$ and $91.7 \%$ respectively with a diagnostic accuracy of $81.7 \%$ at the conventional cut off value of 6 second. Doppler ultrasound, on the other hand had sensitivity and specificity of $100 \%$ and $27 \%$ respectively with a diagnostic accuracy of $52 \%{ }^{[15,16]}$. Starnes et al. ${ }^{[17]}$ raised concerns that the high false negative rate of the modified Allen's test could lead to unnecessary exclusion of some patients by placing some patients at an incorrectly high risk of digit ischemia. They recommended direct digit pressure measurement, which is simpler and more accurate to determine the adequacy of collateral circulation in the hand prior to CABG.

In 1998, Buxton et al ${ }^{[18]}$ were the first to describe the successful use of the ulnar artery as a conduit in a series of 8 patients. The idea of collateral circulation to the hand allowing the use of either the radial or ulnar artery for harvest was reiterated in a larger, more recent study of 25 patients described by Newcomb et al. ${ }^{[19]}$ in 2006. Although, both studies conclude that routine use of the ulnar artery is not recommended due to its close proximity to the ulnar nerve with significant potential for resultant motor and sensory deficits in the hand along with the fact that the ulnar artery tends to be the dominant artery to the hand ${ }^{[18,19]}$.

Another factor to be considered before choosing the RA for graft is the previous use of the conduit for invasive diagnostic procedures, which exposes the artery to post trans-radial access (TRA) occlusion. Interventional cardiologists commonly use the radial artery as access during procedures like percutaneous cardiovascular intervention (PCI) and angiography ${ }^{[20]}$. Our group previously reported significant endothelial damage in the vessel post-TRA leading to reduced vasodilatory function of the vessel with no clear evidence of return of baseline function with time. Along with the biological dysfunction, the risk of RA thrombotic occlusion has been estimated at $7.7 \%$ at 1 day and $5.5 \%$ at $>7$ days after the procedure in a recent large meta-analysis with specific clinical factors (i.e., age, diabetes, reduced artery size, female gender, peripheral vascular disease, smoking, low body weight and lack of statin use) and procedural factors (i.e., use of non-hydrophilic catheters, prolonged postprocedural high pressure compression, etc.) being described as mainly responsible for occurrence of RA occlusion ${ }^{[21]}$. Additionally, an association between TRA and graft occlusion has been described, leading to the recent recommendations on the use of non-punctured RA as graft for $\mathrm{CABG}$ and on the preservation of the RA during angiographic diagnostic procedures in surgical candidates $^{[20,22]}$. In situations with limited graft options, it is recommended that the surgeon should perform Doppler ultrasound preoperatively to positively determine the patency and the diameter of the vessel. The use of the distal end of the artery should also be avoided ${ }^{[22]}$.

It was found that the incidence of the RA graft not being suitable for use after findings of non-satisfactory collateral circulation pre-operatively was around $5 \%{ }^{[23-25]}$. This does not take away from the versatility of the RA graft which can be used as a single free graft, as a Y graft, or as a sequential graft $^{[21]}$.

Apart from the previously mentioned reasons for graft failure amongst venous and arterial grafts, another very important aspect to address is the degree of native artery stenosis when considering the RA for use as conduit. Tatoulis et al. ${ }^{[26]}$ explained that arterial graft patency rate is proportional to native artery stenosis severity so the more severe the stenosis the higher the patency rate of the arterial conduit. Radial arteries are known to be more sensitive and show best results when the native artery has at least $80 \%$ stenosis ${ }^{[26]}$. This phenomenon is termed competitive flow and results in graft failure if the flow through the graft matches flow through the native artery after bypass. Vein grafts do not experience this phenomenon since they have much less resistance with a larger diameter ${ }^{[27]}$.

\section{INTRAOPERATIVE CONSIDERATIONS}

Radial artery graft harvest could be performed open or endoscopically [open radial artery harvest (ORAH) or endoscopic radial artery harvest (ERAH)], preferably from the non-dominant $\operatorname{arm}^{[28]}$. The vessel might be harvested in skeletonized or pedicled fashion. Despite some advocating an advantage in conduit length and 


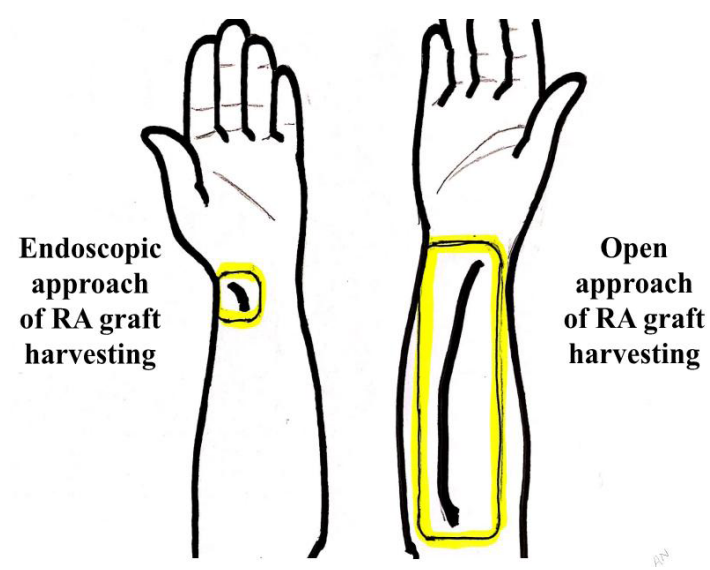

Figure 1. Endoscopic vs, open radial artery (RA) harvesting incision

diameter when harvested in skeletonized fashion $(P<0.01)^{[29]}$, others point out the disadvantage of longer harvesting time and the risk for endothelial damage especially when the Harmonic scalpel is used ${ }^{[30]}$. The Harmonic scalpel uses ultrasonic energy for tissue dissection which is well known to cause increased release of nitric oxide leading to vasodilation and endothelial damage ${ }^{[31]}$. Considering the lack of clear evidence pointing towards a significant improvement in patency rate using the skeletonizing technique, this approach should be discouraged ${ }^{[16]}$.

The open technique requires the forearm to be incised in its entirety. The artery is accessed via a curvilinear incision along the edge of the brachioradialis muscle. The incision is initiated $1 \mathrm{~cm}$ distal to the elbow and extends up to $1 \mathrm{~cm}$ proximal to the wrist. After retraction of the superficial veins, the fascia is incised to expose the radial artery in the mid arm under the belly of brachioradialis muscle [Figure 1] ${ }^{[32]}$.

Endoscopic approach of RA harvesting involves a longitudinal incision about 2-3 cm long proximal to the wrist crease. Dissection is done using bipolar scissors or bisector under direct endoscopic vision. Dissection is done as a pedicle with accompanying venae comitantes included. Carbon dioxide $\left(\mathrm{CO}_{2}\right)$ is insufflated at 10-12 mmHg to provide a working tunnel. Addition of $\mathrm{CO}_{2}$ insufflation prevents spasms in the artery. This is followed by anterior dissection along the radial artery bilaterally up to the level of the antecubital fossa. Posterior dissection is then done up to the level of the radial plexus. Dissection is carried out laterally to achieve adequate branch length for sealing later. Fasciotomy enhances visualization and prevents the development of compartment syndrome. This is followed by branch division using a C-ring to stabilize the pedicle. The graft is then finally retrieved ${ }^{[33]}$.

Navia et al. ${ }^{[34]}$ found that ERAH requires more equipment in comparison with ORAH, hence it is more expensive than ORAH. Shapira et al ${ }^{[35]}$ showed that the cost of an endoscopic kit, including the disposable Harmonic shears, is $\$ 550$. ERAH was also found to take a longer duration as compared to ORAH with an associated steep learning curve in inexperienced hands ${ }^{[36]}$. The reported learning curve for endoscopic harvest ranges from 5 to 30 cases $^{[37]}$. Although, Kiaii et al ${ }^{[38]}$ found that the endoscopic approach requires a significantly lower harvest time $(36.5 \pm 9.4 \mathrm{~min})$ compared to the open approach $(57.7 \pm 9.4 \mathrm{~min})$ when performed by a surgeon adequately experienced in endoscopic harvest.

\section{POSTOPERATIVE OUTCOMES}

\section{Patency rates}

Radial artery as a graft for CABG was first introduced by Carpentier et al ${ }^{[7]}$, in 1973, however, its use was abandoned because of concerns of spasm and intimal hyperplasia. In 1975 , Curtis et al ${ }^{[8]}$ found that in the 
late post-operative period $64.7 \%$ of grafts (22 out of 34 grafts in 29 patients) had occlusive intimal changes. On the other hand, later in the early 90's, Acar et al. ${ }^{[39]}$ demonstrated a $93.5 \%$ patency rate at 9 month followup concluding that the RA was still a reasonable alternative to complement IMA. Ikeda et al ${ }^{[40]}$ found the patency rates of RA graft to be $91 \%$ (24 out 26 grafts), which was comparable to ITA graft patency rate of $97 \%$ (139 out 143 grafts) in the mid post-operative period ( $27 \pm 10$ months). Subsequently, Desai et al ${ }^{[4]]}$ also found that RA grafts were less likely to develop occlusion at one year when compared to saphenous venous grafts. RA grafts were found to have a higher patency rate at 5 year follow up when compared to SVG ${ }^{[42]}$. Angiographic studies have demonstrated a patency rate of $80 \%-90 \%$ at 7-10 year follow-up ${ }^{[43]}$. A more recent study reported an $84.4 \%$ patency rate at 20 years with a probability of graft failure at a similar time to LITA $(19.0 \% \pm 0.2 \% \text { for LITA } v \text { s. } 25.0 \% \pm 0.2 \% \text { for the RA })^{[44]}$.

Moreover, a large patient-level meta-analysis, involving 1,036 patients from 6 trials, comparing RA with saphenous vein grafts showed a significant reduction in the incidence of adverse cardiac events like myocardial infarction, repeat revascularization, and death from cardiac causes with the use of the $\mathrm{RA}^{[9]}$.

Vasospasm was one of the major reasons which lead to a significant degree of reluctance in the use of the RA as a graft conduit in CABG procedures soon after its introduction. These concerns were related to the pronounced muscular profile of the RA wall as opposed to the more elastic wall of the ITA. Perioperative arterial spasm is reported at $0.43 \%$ in all CABG surgeries, and He et al. ${ }^{[45]}$ have suggested this to be an underestimate owing to the chance of mild spasms going unreported. For this reason, a number of pharmacology prophylaxis protocols aimed at avoiding vasospasm have been developed ${ }^{[46]}$. Treatment includes the use of calcium channel blockers with or without long-acting nitrates in the postoperative management of these patients ${ }^{[46]}$ or during surgery as per Reyes et al. ${ }^{[4]}$. Chanda et al ${ }^{[48]}$ recommend a combination of a calcium channel blocker like nifedipine, diltiazem, or verapamil with nitroglycerine for prevention of spasm. Organic nitrates like nitroglycerine have a short half-life but have a faster onset of action as compared to calcium channel blockers like nifedipine, verapamil, etc. These drugs are usually started immediately post operatively and continued for the first postoperative year. However, biological studies have demonstrated a progressive remodeling towards a more elastomuscular phenotype after implantation of the RA as a graft ${ }^{[49]}$, and clinical reports deny a benefit from antispastic pharmacological therapy ${ }^{[50]}$.

\section{COMPARISON OF OUTCOMES BETWEEN ERAH AND ORAH}

Harvesting technique may have an impact on postoperative outcomes and surgical complications. In early experiences in the late 90 's, Royse et al. ${ }^{[51]}$ reported that post-operative numbness and paresthesia of the hand were a commonly observed complication although there was a 98.9\% resolution within 3-6 months after surgery. Neurological complications such as sensory loss occurred in 1.6\%-18.1\%, while motor complications such as diminished thumb strength were observed in $5.5 \%$ of patients in other large series ${ }^{[51-53]}$.

After the introduction of endoscopic harvesting, the incidence of these complications significantly decreased. In an early prospective study from Patel et al. ${ }^{[54]}$ comparing ERAH with ORAH, major neurological complication restricting motor function post-operatively ( $8 \% v$ s. $1 \%$ patients at 1 month, $P<0.05$ ), wound erythema, ecchymosis, mild numbness, or tingling were found to be significantly increased when using open approaches [Table 1].

More recently, the results of a propensity-matched study showed significantly lower hand ischemia (open $7.3 \%$ vs. endoscopic $0 \%, P=0.007$ ), by performing a modified Allen test prior to graft selection to confirm good collateral blood flow to the hand, and wound infection rate in the ERAH group, as well as better minor neurological outcomes (open $19.5 \%$ vs. endoscopic 3.6\%, $P<0.001$ ). Interestingly, freedom from cardiacrelated mortality (open $96.3 \% \pm 2.1 \% v$ s. endoscopic $98.1 \% \pm 1.8 \%, P=0.448$ ) as well as survival free from major cardiac and cerebrovascular adverse events (open $93.9 \% \pm 2.6 \% v$ s. endoscopic $93 \% \pm 3.4 \%, P=0.996$ ) 
Table 1. Comparison between endoscopic vs. open radial artery harvesting ${ }^{[6,11,14-17,33-35,38,45,51,53,54,60,63,64]}$

\begin{tabular}{|c|c|c|c|c|}
\hline & & & ERAH & ORAH \\
\hline \multirow[t]{2}{*}{$\begin{array}{l}\text { Pre-operative } \\
\text { considerations }\end{array}$} & \multicolumn{2}{|l|}{ Patient selection ${ }^{[11,60,63,64]}$} & \multicolumn{2}{|l|}{$\begin{array}{l}\text { Comorbidities: } \\
\text { - Diabetes } \\
\text { - Hypertension }\end{array}$} \\
\hline & \multicolumn{2}{|l|}{ Graft selection $^{[14-17,20]}$} & \multicolumn{2}{|c|}{$\begin{array}{l}\text { Graft patency testing } \\
\text { - Modified Allen's test } \\
\text { - Doppler ultrasound } \\
\text { - Direct digital pressure measurements } \\
\text { Previous trans-radial artery approach }\end{array}$} \\
\hline \multirow{4}{*}{$\begin{array}{l}\text { Operative } \\
\text { factors }\end{array}$} & \multicolumn{2}{|l|}{ Duration $^{[38]}$} & $36.5 \pm 9.4 \mathrm{~min}$ & $57.7 \pm 9.4 \mathrm{~min}$ \\
\hline & \multicolumn{2}{|l|}{ Length of incision ${ }^{[33]}$} & $2-3 \mathrm{~cm}$ long & Full length of the forearm \\
\hline & \multicolumn{2}{|l|}{$\operatorname{Cost}^{[34,35]}$} & $\begin{array}{l}\$ 550 \text { for the endoscopic } \\
\text { kit including the disposable } \\
\text { harmonic shears }\end{array}$ & $\begin{array}{l}\text { Less expensive due to } \\
\text { fewer pieces of equipment } \\
\text { required }\end{array}$ \\
\hline & \multicolumn{2}{|l|}{ Expertise $^{[36]}$} & Steep learning curve & Easier to learn \\
\hline \multirow{14}{*}{$\begin{array}{l}\text { Post- } \\
\text { operative }^{[36,51-54]}\end{array}$} & Hematoma (post operatively) ${ }^{[54]}$ & & $5 / 100$ & $0 / 100$ \\
\hline & Wound infection (post operatively) ${ }^{[54]}$ & & $7 / 100$ & $1 / 100$ \\
\hline & Neuralgia restricting motor function ${ }^{[54]}$ & Post operatively & $10 / 100$ & $1 / 100$ \\
\hline & Neuralgia restricting motor function ${ }^{[54]}$ & At $1 \mathrm{~m}$ & $8 / 100$ & $1 / 100$ \\
\hline & Neuralgia restricting motor function ${ }^{[54]}$ & At $3 \mathrm{~m}$ & $5 / 100$ & $0 / 100$ \\
\hline & Neuralgia restricting motor function ${ }^{[54]}$ & At $6 \mathrm{~m}$ & $1 / 100$ & $0 / 100$ \\
\hline & Ecchymosis (post operatively) ${ }^{[54]}$ & & $21 / 100$ & $2 / 100$ \\
\hline & Wound erythema (post operatively) ${ }^{[54]}$ & & $4 / 100$ & $0 / 100$ \\
\hline & Mild neuralgia $^{[54]}$ & Post operatively & $31 / 100$ & $18 / 100$ \\
\hline & Mild neuralgia ${ }^{[54]}$ & At $1 \mathrm{~m}$ & $26 / 100$ & $8 / 100$ \\
\hline & Mild neuralgia ${ }^{[54]}$ & At $3 \mathrm{~m}$ & $14 / 100$ & $4 / 100$ \\
\hline & Mild neuralgia ${ }^{[54]}$ & At $6 \mathrm{~m}$ & $7 / 100$ & $0 / 100$ \\
\hline & \multicolumn{2}{|c|}{ Patency rate (mid-term follow up period) } & \multicolumn{2}{|l|}{$91 \%$} \\
\hline & \multicolumn{2}{|l|}{ Vasospasm (post operatively) } & \multicolumn{2}{|c|}{$0.43 \%$} \\
\hline
\end{tabular}

ERAH: Endoscopic radial artery harvest; ORAH: open radial artery harvest

at 5 year follow-up were similar among the groups. This suggests that ERAH could provide additional shortterm benefits in terms of improved cosmesis and reduced wound and neurologic complications without compromising the long-term clinical outcomes ${ }^{[55]}$.

These results were confirmed by Burns et al.$^{[56]}$ by demonstrating non-inferiority of ERAH with regards to patency rates at 5 years when compared to ORAH (91.2\% ERAH vs. $87.5 \%$ in ORAH, $P=0.705)$.

Finally, a recent meta-analysis of randomized controlled and propensity matched studies comparing the endoscopic approach of harvesting the RA graft with the open approach demonstrated a lower incidence of wound complications [odds ratio $(\mathrm{OR})=0.33,95 \% \mathrm{CI}$ : 0.14-0.77, $P=0.01$ ] with similar patency rates and early mortality rates $(\mathrm{OR}=1.32,95 \% \mathrm{CI}: 0.76-2.27, P=0.32$ and $\mathrm{OR}=0.78,95 \% \mathrm{CI}: 0.10-6.11, P=0.81)$ [Figure 2] $]^{[57]}$.

Lastly, ERAH has a steep learning curve considering the need to master manipulation of the conduit along with the endoscope which requires an advanced hand-eye coordination. Initial experiences do indeed describe harvest times longer than one hour ${ }^{[58-60]}$ [Table 1], but other reports from the neurosurgical arena, in which the RA is also widely used as a conduit, show that the learning curve associated with the endoscope can be overcome by practice on cadavers ${ }^{[6]]}$.

\section{CONCLUSION}

It is suggested that standard treatment for patients with multivessel disease is use of single or bilateral ITA along with additional arterial conduit ${ }^{[62]}$. When appropriate, the use of RA is recommended over SV graft since it is associated with better 5 year patency rates and improved patient longevity. The RA is preferred in patients at risk for sternal wound complications, such as diabetics who cannot tolerate BITA grafting ${ }^{[18,59]}$. 


\begin{tabular}{|c|c|c|c|c|c|c|}
\hline Study or subgroup & Weight IV & $\begin{array}{l}\text { Odds ratio } \\
\text { andom, } 95 \% \mathrm{Cl}\end{array}$ & \multicolumn{4}{|c|}{$\begin{array}{c}\text { Odds ratio } \\
\text { IV, random, } 95 \% \mathrm{CI}\end{array}$} \\
\hline \multicolumn{7}{|l|}{ 1.1.1 RCT } \\
\hline Nowicki; 2011 & $8.3 \%$ & $0.11[0.01,2.01]$ & & & - & \\
\hline Rudez; 2007 & $53.8 \%$ & $0.37[0.12,1.17]$ & & & & \\
\hline Shapira; 2006 & & Not estimable & & & & \\
\hline Subtotal $(95 \% \mathrm{Cl})$ & $62.2 \%$ & $0.31[0.11,0.92]$ & & & & \\
\hline \multicolumn{7}{|l|}{ Total events } \\
\hline \multicolumn{7}{|c|}{ Heterogeneity: $\mathrm{Tau}^{2}=0.00 ; \chi^{2}=0.60, \mathrm{df}=1(P=0.44) ; P=0 \%$} \\
\hline \multicolumn{7}{|c|}{ Test for overall effect: $Z=2.12(P=0.03)$} \\
\hline \multicolumn{7}{|l|}{ 1.1.2 Matched } \\
\hline Bisleri; 2016 & $8.6 \%$ & $0.07[0.00,1.29]$ & & & & \\
\hline Navia; 2011 & $29.3 \%$ & $0.58[0.12,2.76]$ & & & & \\
\hline Subtotal $(95 \% \mathrm{Cl})$ & $37.8 \%$ & $0.29[0.04,2.00]$ & & & & \\
\hline \multicolumn{7}{|c|}{$\begin{array}{l}\text { Total events } \\
\text { Heterogeneity: } \text { Tau }^{2}=0.78 ; \chi^{2}=1.56, \mathrm{df}=1(P=0.21) ; P^{2}=36 \% \\
\text { Test for overall effect: } Z=1.25(P=0.21)\end{array}$} \\
\hline Total $(95 \% \mathrm{Cl})$ & $100.0 \%$ & $0.33[0.14,0.77]$ & & & & \\
\hline \multicolumn{7}{|c|}{ Total events } \\
\hline \multicolumn{3}{|c|}{$\begin{array}{l}\text { Heterogeneity: } \mathrm{Tau}^{2}=0.00 ; \chi^{2}=2.18, \mathrm{df}=3(P=0.54) ; P^{2}=0 \% \\
\text { Test for overall effect: } Z=2.57(P=0.01) \\
\text { Test for subgroup differences: } \chi^{2}=0.00, \mathrm{df}=1(P=0.95) ; P^{2}=0 \%\end{array}$} & $\frac{1}{0.005}$ & $\begin{array}{c}1 \\
0.1 \\
\text { Favours [ERAH] }\end{array}$ & $\begin{array}{cc}10 & 10 \\
\text { Favours [ORAH] }\end{array}$ & 200 \\
\hline
\end{tabular}

Figure 2. Forest plot of wound infection in endoscopic radial artery harvest (ERAH) vs. open radial artery harvest (ORAH)

The RA offers a decreased risk of atherosclerosis and post-operative complications compared to other graft options like venous grafts. ORAH has a higher risk of wound infection with a larger scar but a shorter harvest time and is easier to learn. ERAH is feasible in all patients when performed by skillful personnel, has fewer arm complications, and provides a higher patient satisfaction with better cosmetic results but takes a longer time to perform when compared to ORAH ${ }^{[58,59]}$ The post-operative cardiac complications and outcomes remain comparable in the two approaches.

\section{DECLARATIONS}

\section{Authors' contributions}

Wrote the paper, created figures for paper: Naik A

Idea generation, helped in writing: Rahouma $\mathrm{M}$

Author for different parts of paper: Rahouma M, Spadaccio C, Khan F

Reviewed and edited of paper: Spadaccio C, Mehta K, Baudo M, Kamel M, Khan F, Hameed I, Wingo M, Ruan Y, Abouarab A, Hossny M, Girardi LN, Gaudino M

Helped with review of figures and tables: Mehta K

Made table for paper: Baudo M

\section{Availability of data and materials}

Data and materials used to help write this article are available for public access.

\section{Financial support and sponsorship}

None.

\section{Conflicts of interest}

All authors declared that there are no conflicts of interest.

\section{Ethical approval and consent to participate}

Not applicable. 


\section{Consent for publication}

Not applicable.

\section{Copyright}

(c) The Author(s) 2018.

\section{REFERENCES}

1. Kolh P, Windecker S, Alfonso F, Collet JP, Cremer J, et al. 2014 ESC/EACTS guidelines on myocardial revascularization: the task force on myocardial revascularization of the European Society of Cardiology (ESC) and the European Association for Cardio-Thoracic Surgery (EACTS) developed with the special contribution of the European Association of Percutaneous Cardiovascular Interventions (EAPCI). Eur J Cardiothorac Surg 2014;46:517-92.

2. Arisha MJ, Ibrahim DA, Abouarab AA, Ahmed MMR, Hussein MKK, et al. Percutaneous coronary intervention in the elderly: current updates and trends. Avialible from: https:/www.researchgate.net/publication/326272491_Percutaneous_coronary_intervention_in_the _ elderly_current_updates_and_trends. [Last accessed on 11 Oct 2018]

3. Martínez-González B, Reyes-Hernández CG, Quiroga-Garza A, Rodríguez-Rodríguez VE, Esparza-Hernández CN, et al. Conduits used in coronary artery bypass grafting: a review of morphological studies. Ann Thorac Cardiovasc Surg 2017;23:55-65.

4. Desai M, Seifalian AM, Hamilton G. Role of prosthetic conduits in coronary artery bypass grafting. Eur J Cardiothorac Surg 2011;40:394-8.

5. Parang P, Arora R. Coronary vein graft disease: pathogenesis and prevention. Can J Cardiol 2009;25:e57-62.

6. Gaudino M, Cellini C, Pragliola C, Trani C, Burzotta F, et al. Arterial versus venous bypass grafts in patients with in-stent restenosis. Circulation 2005;112:I265-9.

7. Carpentier A, Guermonprez JL, Deloche A, Frechette C, DuBost C. The aorta-to-coronary radial artery bypass graft. A technique avoiding pathological changes in grafts. Ann Thorac Surg 1973;16:111-21.

8. Curtis JJ, Stoney WS, Alford WC Jr, Burrus GR, Thomas CS Jr. Intimal hyperplasia. A cause of radial artery aortocoronary bypass graft failure. Ann Thorac Surg 1975;20:628-35.

9. Gaudino M, Benedetto U, Fremes S, Biondi-Zoccai G, Sedrakyan A, et al. Radial-artery or saphenous-vein grafts in coronary-artery bypass surgery. N Engl J Med 2018;378:2069-77.

10. Aldea GS, Bakaeen FG, Pal J, Fremes S, Head SJ, et al. The society of thoracic surgeons clinical practice guidelines on arterial conduits for coronary artery bypass grafting. Ann Thorac Surg 2016;101:801-9.

11. Goldman S, Sethi GK, Holman W, Thai H, McFalls E, et al. Radial artery grafts vs saphenous vein grafts in coronary artery bypass surgery: a randomized trial. JAMA 2011;305:167-74.

12. Schwann TA, Sleiman AKMEH, Yammine MB, Tranbaugh RF, Engoren M, et al. Incremental value of increasing number of arterial grafts: the effect of diabetes mellitus. Ann Thorac Surg 2018;105:1737-44.

13. Hoffman DM, Dimitrova KR, Lucido DJ, Dincheva GR, Geller CM, et al. Optimal conduit for diabetic patients: propensity analysis of radial and right internal thoracic arteries. Ann Thorac Surg 2014;98:30-7.

14. WHO Guidelines on Drawing Blood: Best Practices in Phlebotomy. Geneva: World Health Organization; 2010. Annex I, Modified Allen test. Available from: https://www.ncbi.nlm.nih.gov/books/NBK138652/. [Last accessed on 15 Oct 2018]

15. Jarvis MA, Jarvis CL, Jones PRM, Spyt TJ. Reliability of Allen's test in selection of patients for radial artery harvest. Ann Thorac Surg 2000;70:1362-5

16. Gaudino M, Crea F, Cammertoni F, Mazza A, Toesca A, et al. Technical issues in the use of the radial artery as a coronary artery bypass conduit. Ann Thorac Surg 2014;98:2247-54.

17. Starnes SL, Wolk SW, Lampman RM, Shanley CJ, Prager RL. Noninvasive evaluation of hand circulation before radial artery harvest for coronary artery bypass grafting. J Thorac Cardiovasc Surg 1999;117:261-6.

18. Buxton BF, Chan AT, Dixit AS, Eizenberg N, Marshall RD, et al. Ulnar artery as a coronary bypass graft. Ann Thorac Surg 1998;65:1020-4.

19. Newcomb A, Oqueli E, Buxton BF. Ulnar artery as a coronary artery bypass graft: five-year experience. In: He GW, editor. Arterial grafting for coronary artery bypass surgery. Berlin: Springer; 2006. p. 227-32.

20. Gaudino M, Burzotta F, Bakaeen F, Bertrand O, Crea F, et al. The radial artery for percutaneous coronary procedures or surgery? J Am Coll Cardiol 2018;71:1167-75.

21. Rashid M, Kwok CS, Pancholy S, Chugh S, Kedev SA, et al. Radial artery occlusion after transradial interventions: a systematic review and meta-analysis. J Am Heart Assoc 2016;5:e002686.

22. Mounsey CA, Mawhinney JA, Werner RS, Taggart DP. Does previous transradial catheterization preclude use of the radial artery as a conduit in coronary artery bypass surgery? Circulation 2016;134:681-8.

23. Calafiore AM, Di Giammarco G, Teodori G, D’Annunzio E, Vitolla G, et al. Radial artery and inferior epigastric artery in composite grafts: improved midterm angiographic results. Ann Thorac Surg 1995;60:517-23; discussion 523-4.

24. Brodman RF, Frame R, Camacho M, Hu E, Chen A, et al. Routine use of unilateral and bilateral radial arteries for coronary artery bypass graft surgery. J Am Coll Cardiol 1996;28:959-63. 
25. Risteski PS, Akbulut B, Moritz A, Aybek T. The radial artery as a conduit for coronary artery bypass grafting: review of current knowledge. Anadolu Kardiyol Derg 2006;6:153-62.

26. Tatoulis J, Buxton BF, Fuller JA. Patencies of 2127 arterial to coronary conduits over 15 years. Ann Thorac Surg 2004;77:93-101.

27. Glineur D, Hanet C. Competitive flow and arterial graft a word of caution. Eur J Cardiothorac Surg 2012;41:768-9.

28. Baikoussis NG, Papakonstantinou NA, Apostolakis E. Radial artery as graft for coronary artery bypass surgery: advantages and disadvantages for its usage focused on structural and biological characteristics. J Cardiol 2014;63:321-8.

29. Amano A, Takahashi A, Hirose H. Skeletonized radial artery grafting: improved angiographic results. Ann Thorac Surg 2002;73:1880-7.

30. Rukosujew A, Reichelt R, Fabricius AM, Drees G, Tjan TD, et al. Skeletonization versus pedicle preparation of the radial artery with and without the ultrasonic scalpel. Ann Thorac Surg 2004;77:120-5.

31. Discigil B, King RM, Pearson PJ, Capellini VK, Rodrigues AJ, et al. High-frequency ultrasonic waves cause endothelial dysfunction on canine epicardial coronary arteries. Braz J Cardiovasc Surg 2008;23:190-6.

32. Blitz A, Osterday RM, Brodman RF. Harvesting the radial artery. Ann Cardiothorac Surg 2013;2:533-42.

33. Navia JL, Olivares G, Ehasz P, Gillinov AM, Svensson LG, et al. Endoscopic radial artery harvesting procedure for coronary artery bypass grafting. Ann Cardiothorac Surg 2013;2:557-64.

34. Navia JL, Brozzi N, Chiu J, Blackstone EH, Atik FA, et al. Endoscopic versus open radial artery harvesting for coronary artery bypass grafting. J Cardiovasc Surg (Torino) 2012;53:257-63.

35. Shapira OM, Eskenazi BR, Anter E, Joseph L, Christensen TG, et al. Endoscopic versus conventional radial artery harvest for coronary artery bypass grafting: functional and histologic assessment of the conduit. J Thorac Cardiovasc Surg 2006;131:388-94.

36. Rahouma M, Kamel M, Benedetto U, Ohmes LB, Di Franco A, et al. Endoscopic versus open radial artery harvesting: a meta-analysis of randomized controlled and propensity matched studies. J Card Surg 2017;32:334-41.

37. Krishnamoorthy B, Critchley WR, Venkateswaran RV, Barnard J, Caress A, et al. A comprehensive review on learning curve associated problems in endoscopic vein harvesting and the requirement for a standardised training programme. J Cardiothorac Surg 2016;11:45.

38. Kiaii BB, Swinamer SA, Fox SA, Stitt L, Quantz MA. A prospective randomized study of endoscopic versus conventional harvesting of the radial artery. Innovations (Phila) 2017;12:231-8.

39. Acar C, Jebara VA, Portoghese M, Beyssen B, Pagny JY, et al. Revival of the radial artery for coronary artery bypass grafting. Ann Thorac Surg 1992;54:652-60.

40. Ikeda M, Ohashi H, Tsutsumi Y, Hige K, Kawai T, et al. Angiographic evaluation of the luminal changes in the radial artery graft in coronary artery bypass surgery: a concern over the long-term patency. Eur J Cardiothorac Surg 2002;21:800-3.

41. Desai ND, Cohen EA, Naylor CD, Fremes SE. A randomized comparison of radial-artery and saphenous-vein coronary bypass grafts. N Engl J Med 2004;351:2302-9.

42. Al-Sabti HA, Kindi AA, Al-Rasadi K, Banerjee Y, Al-Hashmi K, et al. Saphenous vein graft vs. radial artery graft searching for the best second coronary artery bypass graft. J Saudi Heart Assoc 2013;25:247-54.

43. Tatoulis J, Buxton BF, Fuller JA, Meswani M, Theodore S, et al. Long-term patency of 1108 radial arterial-coronary angiograms over 10 years. Ann Thorac Surg 2009;88:23-9; discussion 29-30.

44. Gaudino M, Tondi P, Benedetto U, Milazzo V, Flore R, et al. Radial artery as a coronary artery bypass conduit: 20-year results. J Am Coll Cardiol 2016;68:603-10

45. He GW, Taggart DP. Spasm in arterial grafts in coronary artery bypass grafting surgery. Ann Thorac Surg 2016;101:1222-9.

46. Myers MG, Fremes SE. Prevention of radial artery graft spasm: a survey of Canadian surgical centres. Can J Cardiol 2003;19:677-81.

47. Reyes AT, Frame R, Brodman RF. Technique for harvesting the radial artery as a coronary artery bypass graft. Ann Thorac Surg 1995;59:118-26.

48. Chanda J, Brichkov I, Canver CC. Prevention of radial artery graft vasospasm after coronary bypass. Ann Thorac Surg 2000;70:2070-4.

49. Gaudino M, Prati F, Caradonna E, Trani C, Burzotta F, et al. Implantation in coronary circulation induces morphofunctional transformation of radial grafts from muscular to elastomuscular. Circulation 2005;112:I208-11.

50. Patel A, Asopa S, Dunning J. Should patients receiving a radial artery conduit have post-operative calcium channel blockers? Interact Cardiovasc Thorac Surg 2006;5:251-7.

51. Royse AG, Royse CF, Shah P, Williams A, Kaushik S, et al. Radial artery harvest technique, use and functional outcome. Eur J Cardiothorac Surg 1999;15:186-93.

52. Meharwal ZS, Trehan N. Functional status of the hand after radial artery harvesting: results in 3,977 cases. Ann Thorac Surg 2001;72:1557-61.

53. Denton TA, Trento L, Cohen M, Kass RM, Blanche C, et al. Radial artery harvesting for coronary bypass operations: neurologic complications and their potential mechanisms. J Thorac Cardiovasc Surg 2001;121:951-6.

54. Patel AN, Henry AC, Hunnicutt C, Cockerham CA, Willey B, et al. Endoscopic radial artery harvesting is better than the open technique. Ann Thorac Surg 2004;78:149-53.

55. Bisleri G, Giroletti L, Hrapkowicz T, Bertuletti M, Zembala M, et al. Five-year clinical outcome of endoscopic versus open radial artery harvesting: a propensity score analysis. Ann Thorac Surg 2016;102:1253-9.

56. Burns DJP, Swinamer SA, Fox SA, Romsa J, Vezina W, et al. Long-term patency of endoscopically harvested radial arteries: from a randomized controlled trial. Innovations (Phila) 2015;10:77-84.

57. Rahouma M, Kamel M, Benedetto U, Ohmes LB, Di Franco A, et al. Endoscopic versus open radial artery harvesting: a meta-analysis of randomized controlled and propensity matched studies. J Card Surg 2017;32:334-41. 
58. Yoshizaki T, Arai H, Igari T, Tabuchi N, Tanaka H, et al. Endoscopic radial artery harvesting: our initial experience and results of the first 25 patients. Ann Thorac Cardiovasc Surg 2005;11:391.

59. Casselman FP, La Meir M, Cammu G, Wellens F, De Geest R, et al. Initial experience with an endoscopic radial artery harvesting technique. J Thorac Cardiovasc Surg 2004;128:463-6.

60. Karimi A, Ahmadi H, Davoodi S, Movahedi N, Marzban M, et al. Factors affecting postoperative morbidity and mortality in isolated coronary artery bypass graft surgery. Surg Today 2008;38:890-8.

61. Gonzalez LF, Patterson DL, Lekovic GP, Nakaji P, Spetzler RF. Endoscopic harvesting of the radial artery for neurovascular bypass. Neurosurg Focus 2008;24:E10.

62. Buxton BF, Hayward PAR, Newcomb AE, Moten S, Seevanayagam S, et al. Choice of conduits for coronary artery bypass grafting: craft or science? Eur J Cardiothorac Surg 2009;35:658-70.

63. Zacharias A, Schwann TA, Riordan CJ, Durham SJ, Shah AS, et al. Late results of conventional versus all-arterial revascularization based on internal thoracic and radial artery grafting. Ann Thorac Surg 2009;87:19-26.e2.

64. Aronson S, Boisvert D, Lapp W. Isolated systolic hypertension is associated with adverse outcomes from coronary artery bypass grafting surgery. Anesth Analg 2002;94:1079-84, table of contents. 